\title{
Motilin induces gall bladder emptying and antral contractions in the fasted state in humans
}

Y C Luiking, T L Peeters, M F J Stolk, V B Nieuwenhuijs, P Portincasa, I Depoortere, G P van Berge Henegouwen, L M A Akkermans
Department of Surgery

Y C Luiking

V B Nieuwenhuijs

L M A Akkermans

Department of Gastroenterology,

University Hospital

Utrecht, The

Netherlands

M F J Stolk

P Portincasa

G P van Berge

Henegouwen

Gut Hormone

Laboratory, University

of Leuven, Belgium

T L Peeters

I Depoortere

Correspondence to:

Dr Y C Luiking, University Hospital Utrecht,

Department of Experimental

Surgery, G.04.228,

Heidelberglaan 100, 3584

CX Utrecht, The

Netherlands.

Accepted for publication 19 January 1998

\begin{abstract}
Background-Animal studies have shown that motilin affects gall bladder motility. In humans, no effect has been shown, but erythromycin, a motilin receptor agonist, induces gall bladder emptying.

Aims-To explore the effect of increasing doses of exogenous motilin on gall bladder volume and antral contractility in the fasted state in humans.

Methods-After an overnight fast, eight healthy men received increasing intravenous doses of $\mathrm{Leu}^{13}$-motilin (KW5139 ) or $0.9 \% \mathrm{NaCl}$ in a double blind, randomised fashion. Gall bladder volume and antral contraction frequency were determined by ultrasonography.

Results-Infusion of motilin increased plasma motilin levels. Motilin induced a reduction in gall bladder volume of 8.0 (5.0)\%, 17.1 (5.0)\%, $18.5(4.7) \%$, and 16.1 (4.9)\% of baseline volume at the end of infusion of $2,4,8$ and $16 \mathrm{pmol} / \mathrm{kg} / \mathrm{min}$ respectively, compared with mean stable gall bladder volumes during placebo infusion $(p<0.05)$. Antral contraction frequency increased during motilin infusion, but not during placebo infusion $(p<0.05)$. Conclusions-Exogenous motilin reducted fasting gall bladder volume and increased antral contractions. After reaching maximal reduction, the gall bladder volume did not decrease further during continuous motilin infusion at higher doses and stayed at the same reduced volume. The degree of gall bladder volume reduction during motilin infusion mimicked gall bladder emptying preceding antral phase III activity of the migrating motor complex in humans. This study indicates that motilin may play a physiological role in the regulation of gall bladder emptying in the fasted state. (Gut 1998;42:830-835)
\end{abstract}

Keywords: motilin; gall bladder; antrum; motility; ultrasonography

Motilin is a 22 amino acid polypeptide that is produced in enterochromaffin cells in the small intestine. ${ }^{1}$ In the interdigestive state plasma motilin levels show a cyclic variation closely associated with the migrating motor complex (MMC), ${ }^{2-4}$ a cyclic triphasic pattern of aborally propagated (gastro)intestinal contractions. Three phases of the MMC can be distinguished: phase I, motor quiescence; phase II, a period of irregular contractile activ- ity; and phase III, a period of rhythmic contractions with a maximal frequency of two to three contractions per minute in the antrum and 10 to 12 contractions per minute in the duodenum and jejunum. Maximal motilin levels are reached just preceding phase III of the MMC. ${ }^{5}$

Synchronous with the MMC, gall bladder volume fluctuates in the interdigestive state. Interdigestive gall bladder emptying starts in the first half of phase II and the maximal gall bladder volume reduction is reached just before phase III, with subsequent rapid refilling of the gall bladder. ${ }^{6-13} \mathrm{~A}$ small, though significant motilin increase is seen before the onset of gall bladder emptying and a plasma motilin peak is reached 25 minutes after the onset of gall bladder emptying. ${ }^{14}{ }^{15}$ There is a relation between plasma motilin and gall bladder emptying, and the origin of the MMC. Plasma motilin peaks are only associated with MMCs that start in the stomach, ${ }^{5}$ and this observation was confirmed and linked to gall bladder emptying. ${ }^{611}$ Gall bladder contraction and increased plasma motilin levels are recognised in phase II only when phase III is of antral origin, but not when phase III starts in the duodenum. ${ }^{611}$ This observation provides a basis for the wide variation in characteristics of the MMC between individuals and within the same individual, that is known to occur in humans. ${ }^{16}$ No cause for this variability in plasma motilin levels and gall bladder emptying has yet been found.

Exogenous motilin infusion induces an antral phase III in both humans ${ }^{34}$ and dogs, ${ }^{81718}$ but moderate gall bladder contraction has been reported only for dogs, ${ }^{8}{ }^{19}{ }^{20}$ while no effect has been observed in humans. ${ }^{21}$ Furthermore, as manual compression of the gall bladder and infusion of bile in the duodenum provoke a rise in plasma motilin levels, it has been proposed that, in humans, instead of motilin controlling gall bladder emptying, biliary output controls motilin secretion. ${ }^{2122}$ However erythromycin, a motilin receptor agonist, can induce gall bladder contraction in humans. ${ }^{23-29}$ This finding suggests that motilin should have the same effect.

It thus remains unclear whether the rise in plasma motilin is the cause or the consequence of interdigestive gall bladder contractions (and of phase III of the MMC), and also whether these events are related. The enterohepatic circulation of bile acids and interdigestive motility must somehow be associated, as phase III of the MMC plays an important role in the transport of bile acids from the proximal duodenum 
to the distal small intestine, where bile acids are absorbed for transport back to the liver. ${ }^{30}$

As it is unknown whether motilin has an effect on the human gall bladder in the fasted state (and if it does, at what dose), graded motilin infusion was used in this study. The aim of the present study was firstly to explore the effect of graded infusions of motilin on human gall bladder volume in order to determine whether motilin is responsible for gall bladder emptying in the fasted state. Secondly the effect of motilin infusion on antral contractility was studied in order to clarify the role of motilin in gall bladder and antral motility.

\section{Methods}

SUBJECTS

Eight male volunteers were included in the study (mean age 22.1 (SD 3.3) years, BMI $\left.22.4(1.0) \mathrm{kg} / \mathrm{m}^{2}\right)$. All subjects were healthy, non-smokers, and had not used any medication for two weeks preceding the study. Prior to the study, the gall bladder was screened by ultrasonography and one volunteer was excluded because of poor gall bladder visibility. Ultrasonography revealed no gallstones or other abnormalities in the upper digestive tract in any of the subjects.

The protocol was approved by the ethics committee of the University Hospital Utrecht. Informed consent was obtained from each subject.

EXPERIMENTAL PROTOCOL

A randomised, double blind, crossover study design was used to test the effect of motilin versus placebo $(0.9 \% \mathrm{NaCl})$ on gall bladder volume and antral contractions in the fasted state, with concomitant measurement of plasma motilin levels. The effect of motilin and placebo was studied on separate occasions, at a median interval of 5.5 (interquartile range 4-101) days. Each experiment started at 0830 am, after a fasting period of 12 hours; subjects had consumed a low fat diet and no alcohol on the previous day. An indwelling cannula in the antecubital vein of the right arm was used for infusion. A 20 minute saline infusion (1.0 $\mathrm{ml} / \mathrm{min}$ ) was first given for measuring baseline values of gall bladder volume and plasma motilin levels. An infusion of $\mathrm{Leu}^{13}$-motilin (KW5139; Kyowa Hakko Kogyo Co. Ltd, Tokyo, Japan) or placebo was then started. Motilin was infused continuously in four stepwise increased doses: $2,4,8$, and $16 \mathrm{pmol} / \mathrm{kg} / \mathrm{min}$ for $20 \mathrm{~min}$ utes each; the increase was obtained by increasing infusion rates $(0.15,0.30,0.60$, and $1.20 \mathrm{ml} / \mathrm{min}$, respectively) using a syringe infusion pump. The motilin concentration in the infusion syringe was $36.0 \mathrm{ng} / \mathrm{kg} / \mathrm{ml}$, with a total volume of $45 \mathrm{ml}$. Placebo was also infused according to this schedule. The infusion syringes with sterile motilin solutions or placebo were prepared and randomised by the hospital pharmacy. After motilin or placebo infusion the experiment was ended with a subsequent saline infusion for 20 minutes (1.0 $\mathrm{ml} / \mathrm{min}$ ).
An indwelling cannula in the antecubital vein of the left arm was used to take $3.5 \mathrm{ml}$ blood samples for measurement of plasma motilin levels at five minute intervals during the entire experiment. Blood samples were collected in EDTA preloaded tubes (6.8 mg EDTA) and were immediately stored on ice after adding 50 $\mu \mathrm{l} / \mathrm{ml}$ aprotinin (Trasylol, Bayer, Leverkusen, Germany). The plasma was then separated by centrifugation at $4{ }^{\circ} \mathrm{C}$ and stored at $-20^{\circ} \mathrm{C}$ until analysis. Plasma motilin levels were measured by a sensitive and specific radioimmunoassay, as described previously by Peeters et al. ${ }^{2}$ Plasma motilin levels were only measured for the 20 minute period preceding motilin infusion and for the period of motilin infusion. The reason for measuring these plasma levels only was that we were mainly interested in the increase in plasma motilin levels caused by each dose, and the presence of steady state concentrations reached with each dose. A steady state concentration was expected because of the very short half life of motilin, about 4.5 minutes. ${ }^{31}$

During the whole study subjects were asked about possible side effects. At the end of infusion of each dose the subjects were asked about their general well being and about gastrointestinal complaints such as nausea and abdominal discomfort.

\section{ULTRASONOGRAPHY}

Gall bladder volumes were measured by means of real time ultrasonography (Scanner 250, 3.5/5 MHz convex transducer, Pie Medical, Maastricht, The Netherlands). Subcostal sonographic images were obtained with the subject in the supine position. Sonographs were made at five minute intervals. Longitudinal and transverse images of the gall bladder at its largest dimensions were obtained. Gall bladder volume was calculated on line according to the sum of cylinders method. ${ }^{32}$

Sonographs of the gastric antrum were taken at the epigastrium with the subject in the supine position for evaluation of antral contractions. Antral sonographs were made for two minute periods at 10 minute intervals, in between two gall bladder measurements (intervals $0-5,10-15,20-25,30-35,40-45$ minutes, etc.). The first antral measurement was thus made at about two minutes after starting infusion of a certain dose with the second at about 12 minutes after starting this infusion. The ultrasonic probe was placed longitudinally to ensure a single scan comprising the antrum, aorta, and the superior mesenteric vein for standardisation of the scan position. This method has been described by others. ${ }^{29}{ }^{33} 34 \mathrm{An}$ antral contraction was defined sonographically as a thickening of the antral muscle layer with a maximal reduction in the antral area, followed by a relaxation of the muscle layer and increase in the antral area. Antral contraction frequency was defined as the visually complete number of antral contractions within a two minute period. All sonographic images were stored on videotape. The antrum was not clearly visible ultrasonographically in one subject and therefore 


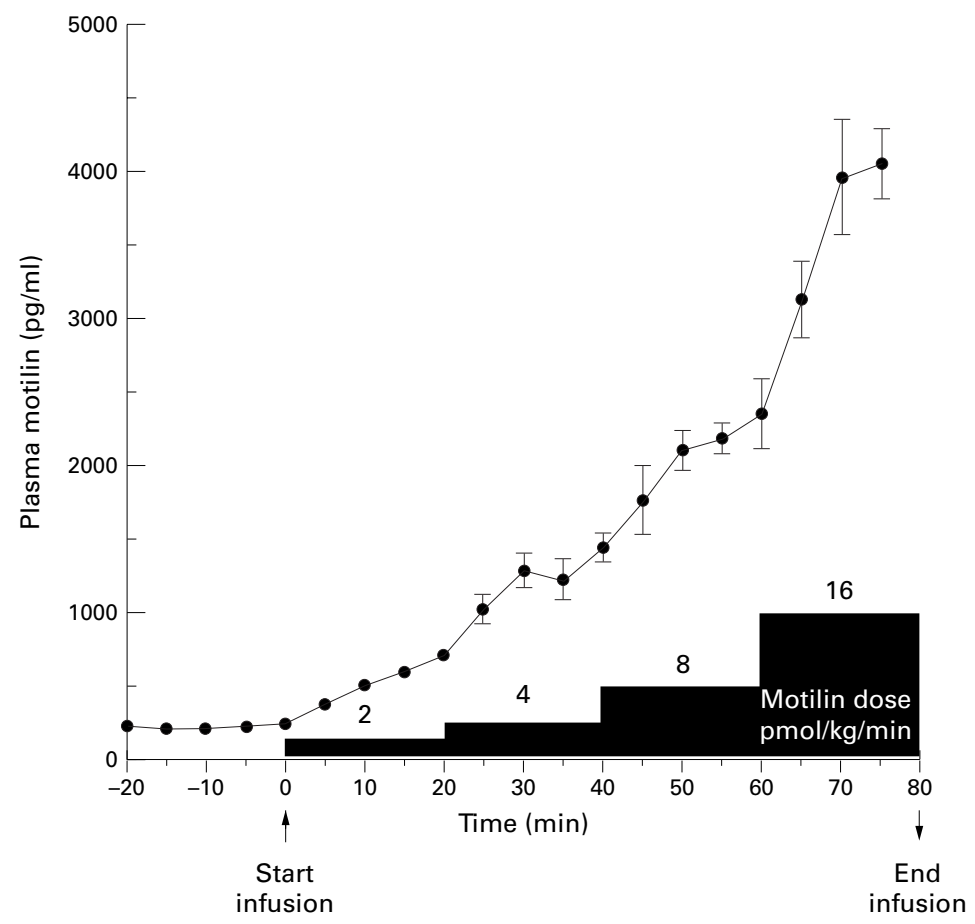

Figure 1 Plasma motilin levels before and during infusion of stepwise increased doses of motilin (means (SEM)). Horizontal bars show the motilin dose.

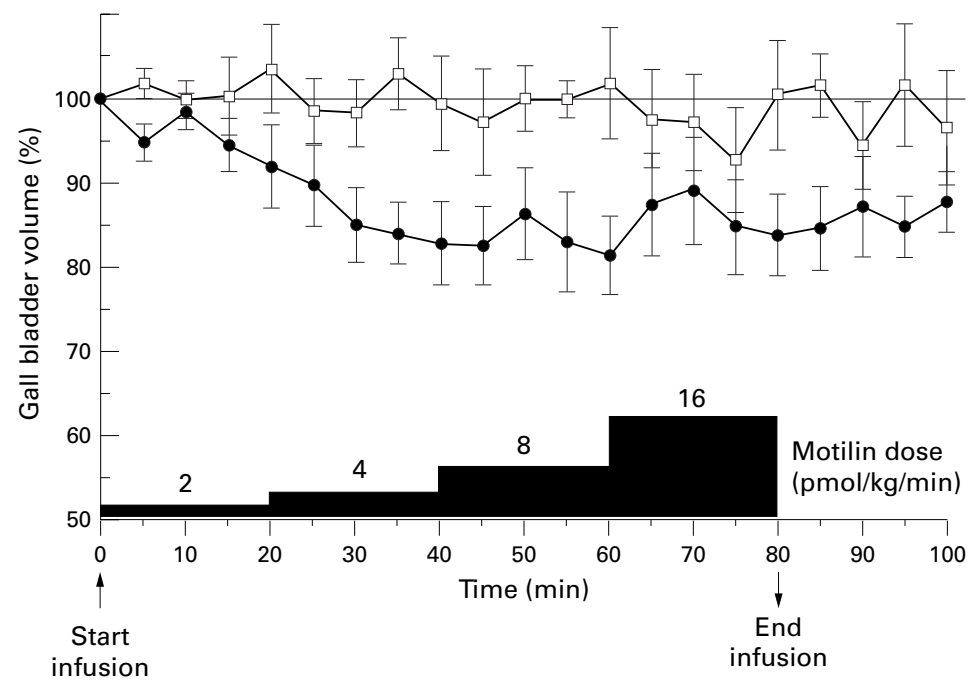

Figure 2 Effect of motilin (closed circles) versus placebo (saline; open squares) infusion on gall bladder volume (mean (SEM)). Gall bladder volumes are expressed as percentages of the baseline volume. Horizontal bars show the motilin dosage. $p<0.05$ for motilin versus placebo.

antral contraction frequencies could be determined in only seven subjects.

DATA ANALYSIS

The baseline gall bladder volume was determined as the mean of five gall bladder volume measurements taken at five minute intervals during the first 20 minutes of saline infusion preceding motilin or placebo infusion. Gall bladder volumes during motilin or placebo infusion were expressed as percentages of baseline volume. All values of gall bladder volumes presented are therefore relative values. The mean numbers of antral contractions per two minutes were calculated separately for three periods (before, during, and after infu- sion) for each individual. To analyse the effect of different doses of motilin on antral contraction frequency, only the second of two measurements (taken 10-15 minutes after start of infusion of that dose) was considered to be representative of that dose.

\section{STATISTICAL ANALYSIS}

The gall bladder volumes and plasma motilin levels are expressed as means (SEM) $(n=8)$. Antral contractions per two minutes are expressed as medians with interquartile ranges $(n=7)$. Differences in gall bladder volumes between motilin and placebo infusion, taking into account possible dose or time effects, were evaluated by repeated measures analysis of variance. When a significant difference was detected, the results were further compared for contrasts by using univariate $F$ tests. Differences in the maximal gall bladder volume reduction between motilin and placebo were evaluated with Student's $t$ test for paired data. Differences in plasma motilin levels between each dose of motilin and within each dose were evaluated by repeated measures analysis of variance. Data on antral contraction frequency did not follow a normal distribution and therefore required non-parametric tests. Antral contraction frequencies before, during, and after infusion were compared by means of the Wilcoxon matched pairs, signed rank test. Antral motility data for each dose of motilin were compared using Friedman's test and Student-Newman Keuls' test. Statistical significance was defined as a two tailed probability of less than 0.05 .

\section{Results}

No complaints during and after motilin infusion were reported by the subjects. Four participants reported a strong feeling of hunger during motilin infusion, but this feeling was not dose related.

\section{PLASMA MOTILIN LEVELS}

Baseline plasma motilin levels were 217.9 (9.6) $\mathrm{pg} / \mathrm{ml}$ before infusion. Plasma motilin levels at the end of motilin infusion at 2, 4, 8, and 16 $\mathrm{pmol} / \mathrm{kg} / \mathrm{min}$ were $385.1 \quad(64.0), 1024.7$ (137.7), 1992.5 (100.3), and 3863.5 (240.0) $\mathrm{pg} / \mathrm{ml}$, respectively (fig 1). Plasma motilin levels differed significantly between each successive dose $(p<0.05)$. Significant increases in plasma motilin levels were observed for each dose until 10 minutes after the start of infusion of that dose $(p<0.05)$. From 10 minutes of infusion there were no further significant changes in plasma motilin levels for doses of 4 , 8 , and $16 \mathrm{pmol} / \mathrm{kg} / \mathrm{min}$ motilin. However plasma motilin levels continued to increase significantly after 10 minutes for the $2 \mathrm{pmol} / \mathrm{kg} /$ min dose $(p<0.05)$.

\section{GALL BLADDER VOLUME}

The mean baseline gall bladder volume during the first 20 minute period of saline infusion was $33.0(3.6) \mathrm{ml}$ and 33.9 (5.1) $\mathrm{ml}$ before motilin and placebo infusion were started, respectively (NS). Figure 2 shows the effect of increasing doses of motilin on gall bladder volume. 
Table 1 Maximal gall bladder volume $(G B V)$ reduction per individual and the corresponding time when this maximal reduction was reached for motilin and placebo (saline)

\begin{tabular}{|c|c|c|c|c|}
\hline \multirow[b]{2}{*}{ Subject } & \multicolumn{2}{|l|}{ Saline } & \multicolumn{2}{|l|}{ Motilin } \\
\hline & $\begin{array}{l}\text { Maximal GBV } \\
\text { reduction (\%) }\end{array}$ & $\begin{array}{l}\text { Time (min) from } \\
\text { start of infusion }\end{array}$ & $\begin{array}{l}\text { Maximal GBV } \\
\text { reduction (\%) }\end{array}$ & $\begin{array}{l}\text { Time (min) from } \\
\text { start of infusion }\end{array}$ \\
\hline 1 & 35.4 & 75 & 28.7 & 50 \\
\hline 2 & 14.8 & 30 & 27.6 & 50 \\
\hline 3 & 10.7 & 75 & 36.5 & 40 \\
\hline 4 & 16.6 & 100 & 42.5 & 65 \\
\hline 5 & 26.8 & 45 & 6.7 & 5 \\
\hline 6 & 28.9 & 75 & 31.1 & 45 \\
\hline 7 & 32.7 & 45 & 20.6 & 60 \\
\hline 8 & 1.2 & 55 & 29.6 & 40 \\
\hline Mean (SEM) & $20.9(4.2)$ & $62.5(8.0)$ & $27.9(3.8)$ & $44.4(6.4)$ \\
\hline
\end{tabular}

Motilin caused a significant reduction in gall bladder volume compared with placebo $(p<0.05)$, but this reduction was not dose related. The gall bladder volume was reduced significantly starting 30 minutes after the beginning of motilin infusion $(p<0.05)$. There was no further reduction from 45 minutes after the start of infusion when the mean gall bladder volume was $82.6(4.6) \%$ of baseline. Volume remained stable during the rest of the motilin infusion. At the end of motilin infusion at $2,4,8$, and $16 \mathrm{pmol} / \mathrm{kg} / \mathrm{min}$ mean gall bladder volumes were, respectively, $92.0(5.0) \%$, $82.9(5.0) \%, 81.5(4.7) \%$, and 83.9 (4.9)\% of baseline gall bladder volume. Twenty minutes after the end of motilin infusion, the mean gall bladder volume reached a level of 87.9 (3.6)\% of baseline gall bladder volume. The maximal gall bladder volume reduction during motilin infusion was reached within 40-65 minutes, except in one subject who did not respond to motilin infusion with a clear reduction in gall bladder volume. During placebo infusion maximal gall bladder volume reduction was randomly achieved (30-100 minutes).

Table 1 shows the maximal gall bladder volume reduction per individual (as a percentage of baseline volume) and time (in minutes from the start of infusion) when this maximal reduction was reached, for both motilin and placebo. The mean time interval between start of infusion and reaching maximal gall bladder volume reduction was not significantly different between motilin and placebo $(p=0.06)$. The maximal reduction in gall bladder volume was 27.9 (3.8)\% during motilin infusion and

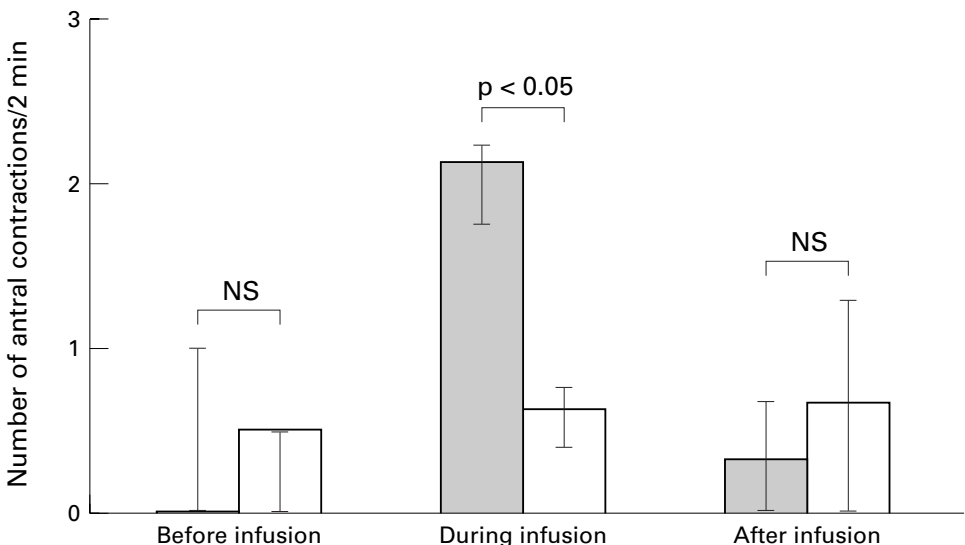

Figure 3 Antral contraction frequency (median and interquartile range) during the 20 minute period before infusion, the 80 minute period of infusion, and the 20 minute period after infusion of motilin (shaded column) and of placebo (open column).
20.9 (4.2)\% during placebo infusion (NS). One of the subjects did not respond to motilin infusion with a gall bladder volume reduction, the gall bladder volume remaining constant throughout the study. When this subject was excluded from analysis there was still no difference in maximal gall bladder volume reduction between motilin and placebo treatment.

ANTRAL CONTRACTILITY

Figure 3 shows the antral contraction frequency (number of contractions per two minutes) during the 20 minute period before infusion of motilin or placebo, during infusion, and during the 20 minute period after infusion, respectively. The number of contractions during motilin infusion was increased significantly compared with that during placebo (median 2.13 (interquartile range 1.75-2.25) for motilin and $0.63(0.38-0.75)$ contractions per two minutes for placebo; $p<0.05)$. The number of antral contractions during the 20 minutes preceding the motilin infusion did not differ from that preceding the placebo infusion. The number of antral contractions during the 20 minutes after the end of the motilin infusion did not differ from that after the end of the placebo infusion. No dose dependent effect of motilin on antral contractility was observed. Antral contraction frequency increased after the start of motilin infusion, reaching a maximum (four to six contractions per two minutes) at $10-15$ to $30-35$ minutes after the start of infusion. Frequencies of antral contractions never exceeded six contractions per two minutes, during both motilin and placebo infusions.

\section{Discussion}

Motilin has, until now, been known as an important hormone in the regulation of gastrointestinal motility in humans. Gastrointestinal motility, characterised by the cyclic pattern of the MMC, is related to various gastrointestinal events such as gastric acid production, pancreatic secretion, and gall bladder emptying. It has, however, been unclear whether motilin was responsible for gall bladder emptying. To our knowledge, this is the first study showing that exogenous motilin causes a reduction in gall bladder volume in the fasted state in humans. Continuous infusion with stepwise increased doses of motilin resulted in a maximal gall bladder volume reduction of about $30 \%$, a value comparable to 
the gall bladder volume reduction preceding an antral phase III of the MMC under normal physiological conditions. ${ }^{6}$ This suggests that gall bladder emptying in the fasted state is only partial and reaches a maximum of about $30 \%$.

Plasma motilin levels showed stepwise increases in our study, reaching steady state concentrations after 10 minutes infusion at the three highest motilin doses. The absence of a steady state concentration with the lowest dose of $2 \mathrm{pmol} / \mathrm{kg} / \mathrm{min}$ motilin may be explained by a stronger influence of fluctuating endogenous motilin concentrations at this dose. As exogenous motilin induces release of endogenous motilin, ${ }^{35}{ }^{36}$ plasma motilin levels measured in our study were the result of both endogenous and exogenous motilin. The release of endogenous motilin by exogenous motilin is dose related for low doses, ${ }^{35}$ but seems not to be dose related for higher doses. ${ }^{36}$ This observation may explain the absence of a steady state with the lowest dose of $2 \mathrm{pmol} / \mathrm{kg} / \mathrm{min}$.

Substitution in human motilin of residue 13 (methionine) does not affect gastroduodenal motor activity. Furthermore identical biological activity of the $\mathrm{Met}^{13}$ substituted motilins is also suggested by in vitro studies during pharmacological blockade of neural pathways. ${ }^{37}$ The Leu ${ }^{13}$ analogue of human motilin, used in our study, will therefore have the same effects as human motilin.

The only previous study on the effect of exogenous motilin infusion on the human gall bladder was published by Svenberg et al in $1984 .{ }^{21}$ Pure porcine motilin was infused for 60 minutes at two different concentrations, which increased plasma motilin by $40 \mathrm{pmol} / \mathrm{l}$ (physiological) and $200 \mathrm{pmol} / \mathrm{l}$ (supraphysiological), respectively, but did not affect gall bladder emptying in five subjects. However, Svenberg et al's results may have been affected by their experimental technique. These authors used technetium-99m labelled HIDA scintigraphy to measure gall bladder emptying. However, when ${ }^{99 m}$ Tc-HIDA is given as a bolus (unclear from the paper), only bile flow is observed, but changes in gall bladder volume are not detectable. ${ }^{38}$ Moreover, one episode of gall bladder emptying had passed before the start of motilin infusion, at which time most of the radioactive marker may already have vanished from the liver and the gall bladder. Furthermore, reuptake of the label by the liver would not occur as the label, ${ }^{99 \mathrm{~m}}$ Tc-HIDA, is not absorbed in the distal small intestine. The ultrasound technique used in our study, and in others on the effect of erythromycin on the human gall bladder, ${ }^{23-29}$ may therefore reflect the true gall bladder volume and contraction. The mean time interval between start of infusion and maximal gall bladder volume reduction tended to be shorter for motilin compared with placebo, although this difference was not statistically significant. However we believe that the observation that gall bladder emptying was randomly achieved with placebo and synchronised with motilin is more relevant.

We found that the contractile effects of motilin on the gall bladder in the fasted state are in agreement both with effects reported for erythromycin, a motilin receptor agonist, on the human gall bladder, ${ }^{23-29}$ and with results of animal studies using motilin and motilides. ${ }^{81920}$ The dose effect relation differs, however. The effect of erythromycin on human gall bladder volume is dose dependent until a plateau in gall bladder volume reduction of $40-45 \%$ of baseline volume is reached..$^{25}$ In humans, motilide EM523 also induces dose dependent gall bladder emptying which is identical to the emptying which occurs during the interdigestive state. ${ }^{20}$ In dogs, the contractile response of the gall bladder is not dose related, but motilin induced gall bladder contractions start with dose related periods of latency and return to preinfusion levels before cessation of motilin infusion. ${ }^{8}{ }^{19}$ However, none of these studies in humans and dogs infused stepwise increased doses of erythromycin, EM523, or motilin, as we did in our study. We observed that the reduction in gall bladder volume started after 30 minutes of infusion (with a motilin dose as low as $4 \mathrm{pmol} / \mathrm{kg} / \mathrm{min}$ ) and continued until a plateau was reached 45 minutes after the start of infusion. Our results suggest that infusion of motilin in stepwise increased doses, resulting in a constant rise in plasma motilin, overcomes desensitisation, resulting in maintenance of low gall bladder volume. We did not find a dose dependent effect of motilin on gall bladder volume reduction, but this may be the result of the study design with stepwise increased doses without a washout time between each dose. The stimulus for gall bladder volume reduction in the fasted state may therefore be the sudden rise in plasma motilin level itself, rather than a continuously high motilin level per se. This idea is supported by the observation made under normal physiological conditions, of a small but significant increase in plasma motilin level before the onset of gall bladder emptying. ${ }^{14}{ }^{15}$ Our study, while it does not provide additional information about the mechanism by which motilin may reduce gall bladder volume in the fasted state, offers support for the hypothesis that motilides act via motilin receptors in humans.

Although ultrasonography, as used in our study, is not an optimal method for studying antral motility, the results show a motilin induced increase in antral contractions. As motilin infusion did not induce continuously high antral contraction frequencies, motilin tachyphylaxis or periods of decreased sensitivity for motilin may be present during which antral contractions cannot be induced. ${ }^{39}{ }^{40} \mathrm{We}$ cannot, however, exclude missing antral contractions, as antral contractions were monitored for only two minutes once every $10 \mathrm{~min}$ utes. In order to draw definite conclusions about the effects of motilin on cyclic antral motility and the correlation with gall bladder emptying, continuous gastrointestinal motility recordings combined with gall bladder ultrasonography are necessary.

In conclusion, our study showed that exogenous motilin induces a partial reduction in gall bladder volume together with an increase 
in antral contractility. Motilin may therefore play a physiological role in the regulation of gall bladder emptying in the fasted state, in addition to its known role in the regulation of antral contractility. Further studies are needed with simultaneous recording of gall bladder volumes and continuous antroduodenal manometry.

Leu $^{13}$-motilin (KW-5139) was kindly provided by Kyowa Hakko Kogyo Co. Ltd, Tokyo, Japan. P C van de Meeberg is acknowledged for his assistance with ultrasonography. This study was supported by The Netherlands Organisation for Scientific Research, Council for Medical and Health Research (NWOGMW) Grant 900-522-140. This work has been presented in abstract form at the 11th International Symposium on Regulatory Peptides, Copenhagen, September 1996 (Regul Pept 1996;64:114).

1 Brown JC, Mutt V, Dryburgh J. The further purification of motilin, a gastric motor activity stimulating polypeptide from the mucosa of the small intestine of hogs. Can $\mathcal{F}$ Physiol Pharmacol 1971;49:399-405.

2 Peeters TL, Vantrappen G, Janssens J. Fasting plasma motilin levels are related to the interdigestive motility complex. Gastroenterology 1980;79:716-19.

Gastroenterology 1980;79:716-19.
3 Vantrappen G, Janssens J, Peeters TL, et al. Motilin and the Vantrappen G, Janssens J, Peeters TL, et al. Motilin and the interdigestive mig

4 Boivin M, Raymond MC, Riberdy M, et al. Plasma motilin variation during the interdigestive and digestive states in man. F Gastrointest Motil 1990;2:240-6.

5 Bormans V, Peeters TL, Janssens J, et al. In man, only activity fronts that originate in the stomach correlate with motilin peaks. Scand $\mathcal{F}$ Gastroenterol 1987;22:781-4.

6 Stolk MFJ, van Erpecum KJ, Smout AJPM, et al. Motor cycles with phase III in antrum are associated with high motilin levels and prolonged gall bladder emptying. Am $f$ Physiol 1993;264:G596-600.

7 Owyang C, Achem-Karam SR, Vinik AI. Pancreatic polypeptide and intestinal migrating motor complex in humans. Effect of pancreaticobiliary secretion. Gastroenterology 1983;84:10-17.

8 Itoh Z, Takahashi I. Periodic contractions of the canine gall bladder during the interdigestive state. Am f Physiol 1981; 240:G183-9.

9 Peeters TL, Vantrappen G, Janssens J. Bile acid output and the interdigestive migrating motor complex in normals and in cholecystectomy patients. Gastroenterology 1980;79:67881.

10 Scott RB, Diamant SC. Do motilin and pancreatic polypeptide regulate duodenal bile acid delivery? Can $\mathcal{f}$ Physio Pharmacol 1988;66:1499-504.

11 Kusano M, Sekiguchi T, Nishioka T, et al. The relationship between interdigestive gall bladder and gastroduodenal motility in man. Gastroenterol fpn 1990;25:568-74.

12 Kraglund K, Hjerlind J, Jensen FT, et al. Gall bladder emptying and gastrointestinal cyclic motor activity in humans. Scand $\mathcal{F}$ Gastroenterol 1984;19:990-4.

13 Marzio L, Neri M, Capone F, et al. Gall bladder contraction and its relationship to interdigestive duodenal motor activand in relationship to interdigestive duodenal motor activ-

14 Svenberg T, Christofides ND, Fitzpatrick ML, et al. Interdigestive biliary output in man: relationship to fluctuations in gestive biliary output in man: relationship to fluctuations in

plasma motilin and effect of atropine. Gut 1982;23:1024-8.
15 Ovist N, Oster-Jorgensen E, Pedersen SA, et al. Increases in plasma motilin follow each period of gall bladder emptying plasma motilin follow each period of gall bladder emptying during the interdigestive period and changes in serum bile acid concentration correlate

16 Dooley CP, Di Lorenzo C, Valenzuela JE. Variability of migrating motor complex in humans. Dig Dis Sci 1992;37: $723-8$.

17 Yokohata $\mathrm{K}$, Kimura $\mathrm{H}$, Ogawa $\mathrm{Y}$, et al. Biliary motility. Changes in detailed characteristics correlated to duodenal
migrating motor complex and effects of morphine and motilin in dogs. Dig Dis Sci 1994;39:1294-301.
18 Lee KY, Park HJ, Chang TM, et al. Cholinergic role on release and action of motilin. Peptides 1983;4:375-80.

19 Takahashi I, Suzuki T, Aizawa I, et al. Comparison of gall bladder contractions induced by motilin and cholecystokinin in dogs. Gastroenterology 1982;82:419-2

20 Itoh Z, Mizumoto A, Ohtawa M, et al. Motilide (EM523) mimics motilin in interdigestive gall bladder contraction in the dog and man [abstract]. Gastroenterology 1991;100: A320.

21 Svenberg TI, Nilsson I, Samuelson K, et al. Studies on the causal relationship between gall-bladder emptying and motilin release in man. Acta Chir Scand 1984;(suppl 520): 59-61.

22 Nilsson BI, Svenberg T, Tollström T, et al. Relationship between interdigestive gall bladder emptying, plasma motilin and migrating motor complex in man. Acta Physiol Scand 1990;139:55-61.

23 Catnach SM, Fairclough PD, Trembath RC, et al. Effect of oral erythromycin on gall bladder motility in normal subjects and subjects with gallstones. Gastroenterology 1992;102:2071-6.

24 Fiorucci S, Scionti L, Bosso R, et al. Effect of erythromycin on gall bladder emptying in diabetic patients with and without autonomic neuropathy and high levels of motilin. Dig Dis Sci 1992;37:1671-7.

25 Fiorucci S, Bosso R, Morelli A. Erythromycin stimulates gall bladder emptying and motilin release by atropinesensitive pathways. Dig Dis Sci 1992;37:1678-84

26 Jebbink MCW, Masclee AAM, van der Kleij FGH, et al. Effect of loxiglumide and atropine on erythromycininduced reduction in gall bladder volume in human subjects. Hepatology 1992;16:937-42.

27 Masclee AAM, Ledeboer ML, Gielkens HG, et al. Effect of erythromycin on gall bladder emptying in patients with antrectomy or truncal vagotomy. $A m \mathcal{F}$ Gastroenterol 1995;90:973-7.

28 Fiorucci S, Santucci L, Morelli A. 5-Hydroxytryptamine 3-receptor antagonist modulates gall bladder emptying and motilin release induced by erythromycin. Dig Dis Sci 1993; 38:2236-40

29 Fiorucci S, Distrutti E, Quintieri A, et al. L-arginine/nitric oxide pathway modulates gastric motility and gall bladder emptying induced by erythromycin and liquid meal in humans. Dig Dis Sci 1995;40:1365-71.

30 Qvist N, Pedersen SA, Oster-Jorgensen E, et al. The migrating motor complex and the enterohepatic circulation of bile acids: a scintigraphic study using ${ }^{75} \mathrm{Se}-\mathrm{HCAT}$. $\mathcal{F}$ Gastrointest Motil 1991;3:1-4.

31 Mitznegg P, Bloom SR, Domschke W, et al. Pharmacokinetics of motilin in man. Gastroenterology 1977;72:413-16.

32 Everson GY, Braverman DZ, Johnson ML, et al. A critical evaluation of real-time ultrasonography for the study of gall bladder volume and contraction. Gastroenterology 1980;79: $40-6$.

33 Bolondi L, Bortolotti M, Santi V, et al. Measurement of gastric emptying time by real-time ultrasonography. Gastroen

34 Portincasa P, Di Ciaula A, Palmieri V, et al. Effects of cholestyramine on gall bladder and gastric emptying in
obese and lean subjects. Eur F Clin Invest 1995;25:746-53.

35 Hall KE, Greenberg GR, El-Sharkawy TY, et al. Relationship between porcine motilin-induced migrating motor complex-like activity, vagal integrity, and endogenous motilin release in dogs. Gastroenterology 1984;87:76-85.

36 Mochiki E, Satoh M, Tamura T, et al. Exogenous motilin stimulates endogenous release of motilin through cholinergic muscarinic pathways in the dog. Gastroenterology 1996; 111:1456-64.

37 Strunz U, Domschke W, Domschke S, et al. Gastroduodenal motor response to natural motilin and synthetic position 13-substituted motilin analogues: a comparative in vitro study. Scand $\mathcal{F}$ Gastroenterol 1976;11:199-203.

38 Qvist N. Motor activity of the gall bladder and gastrointestinal tract as determinants of enterohepatic circulation. A scintigraphic and monometric study. Dan Med Bull 1995;42:426-40.

39 Parkman HP, Pagano AP, Vozzelli MA, et al. Gastrokinetic effects of erythromycin and neurogenic mechanisms of action in rabbit stomach. Am f Physiol 1995;269:G418-26.

40 Takahashi I, Honda R, Dodds WJ, et al. Effect of motilin on the opossum upper gastrointestinal tract and sphincter of Oddi. Am f Physiol 1983;245:G476-81. 